\title{
Tungstate is an effective antidiabetic agent in streptozotocin-induced diabetic rats: a long-term study
}

\author{
A. Barberà ${ }^{1}$, R.R. Gomis ${ }^{1}$, N.Prats ${ }^{2}$, J.E.Rodríguez-Gil ${ }^{3}$, M.Domingo ${ }^{2}$, R.Gomis ${ }^{4}$, J.J. Guinovart ${ }^{1}$ \\ ${ }^{1}$ Department of Biochemistry and Molecular Biology, University of Barcelona, Spain \\ ${ }^{2}$ Department of Histology and Animal Pathology, Autonomous University of Barcelona, Spain \\ ${ }^{3}$ Department of Animal Reproduction, Autonomous University of Barcelona, Spain \\ ${ }^{4}$ Endocrinology and Diabetes Unit, Medicine Department. Agustí Pi i Sunyer Institute of Biomedical Research, \\ Hospital Clínic i Universitari, Barcelona, Spain
}

\begin{abstract}
Aims/hypothesis. Recent studies have shown the anti diabetic effects of oral sodium tungstate treatment in several animal models of diabetes based on shortterm experiments. In this study, we examined the effectiveness of long-term tungstate treatment of streptozotocin-induced-diabetic rats.

Methods. Tungstate was administered to the drinking water of rats for eight months.

Results. The treatment resulted in a reduction in serum glucose concentrations in diabetic rats, but no change in glycaemia was detected in healthy rats. Alterations in the hepatic glucose metabolism due to diabetes were almost completely counteracted by tungstate treatment. The partial recovery of glucokinase activity, not found in diabetic animals, normalised glycogen and glucose 6-phosphate concentrations.
\end{abstract}

Tungstate treatment also restored pyruvate kinase activity and fructose 2,6-bisphosphate concentrations. In healthy rats, tungstate treatment did not modify the majority of the hepatic parameters studied. Moreover, tungstate treatment prevented diabetes-induced morphological changes in the kidney and ocular lens and also reduced mortality. Furthermore, no hypoglycaemic episodes or undesirable side effects were observed in treated diabetic or healthy rats. In addition, there is no evidence of intolerance developing after prolonged use.

Conclusion/interpretation. Tungstate could play a helpful part in the long-term treatment of diabetes. [Diabetologia (2001) 44: 507-513]

Keywords Tungstate, STZ-diabetic rats, liver, insulinlike, glucose metabolism, glycaemia.
Insulin is the cornerstone of Type I (insulin-dependent) diabetes mellitus treatment and of some forms of Type II (non-insulin-dependent) diabetes mellitus treatment. It is only, however, effective when injected. An oral substitute would therefore increase the comfort of diabetic patients and also improve the control of blood glucose concentrations [1]. In recent years, several inorganic compounds have been identified as possessing insulinomimetic properties when

Received: 10 October 2000 Accepted: 4 December 2000

Corresponding author: J.J. Guinovart, $\mathrm{PhD}$, Departament de Bioquímica i Biologia Molecular, Universitat de Barcelona, Martí i Franquès, 1, E-08028 Barcelona, Spain

Abbreviations: Glu 6-P, glucose 6-phosphate; Fru-2,6- $\mathrm{BP}_{2}$, fructose 2,6-bisphosphate; STZ, streptozotocin. given orally to diabetic rats - vanadate and derivates [2-6], selenate $[7,8]$, tungstate $[9,10]$ and molibdate $[11,12]$ - or to diabetic patients $[13,14]$. Tungstate has been reported to be an effective hypoglycaemic agent in two animal models of diabetes mellitus: STZ-diabetic rats (model of Type I diabetes) [9], and nSTZ-diabetic rats (model of Type II diabetes in neonatal STZ-induced diabetic rats) [10]. These were, however, short-term studies in which tungstate was given for only 2 weeks. We evaluated the therapeutic effects of the oral administration of tungstate for 8 months on STZ-diabetic rats. The data shows that the compound reduces glycaemia and keeps it normalised throughout the treatment. Tungstate treatment also prevents the occurrence of various complications of diabetes in treated diabetic rats and does not cause any undesirable side effects. Moreover, 
there is no evidence suggesting intolerance develops after prolonged use. Finally, we show that tungstate treatment in diabetic rats does not produce any hypoglycaemic episode, one of the major drawbacks of insulin treatment.

\section{Materials and methods}

Materials. Sodium tungstate was purchased from Carlo Erba (Milan, Italy) and STZ from Sigma (St. Louis, Mo., USA). Enzymes and biochemical reagents were either from Roche Diagnostic Gmbh (Mannheim, Germany) or Sigma. All other reagents were of analytical grade.

Animals and experimental design. Adult male Wistar (200 g) rats were kept under a constant 12-hour light-dark cycle and were allowed to eat and drink freely. Diabetes was induced by a single intraperitoneal injection of STZ $(70 \mathrm{mg} / \mathrm{kg}$ body weight) in $0.9 \% \mathrm{NaCl}$ with $100 \mathrm{mmol} / \mathrm{l}$ sodium citrate buffer ( $\mathrm{pH}$ 4.5). Diabetes was confirmed by determination of glycaemia (Reflotron, Roche Diagnostic). Treatment started 7 to 10 days after an STZ injection. Diabetic and healthy rats were divided into two groups. In the first (untreated) group, rats received deionized drinking water; in the second (treated) group, they were given a solution of sodium tungstate. During the first 3 weeks of treatment the rats received a solution of $0.7 \mathrm{mg} / \mathrm{ml}$ and after those 3 weeks, the concentration of tungstate was increased to $2 \mathrm{mg} / \mathrm{ml}$. The treatment was carried out for 8 months. During this period, fluid and food intake were measured every day between 0900 and $1100 \mathrm{~h}$. Body weight and blood glucose concentrations were measured once a week.

At the end of the experiment rats were anesthetized with diethylether and killed by decapitation between 0900 and $1100 \mathrm{~h}$. Blood samples were immediately collected on EDTA. After centrifugation at $1000 \mathrm{~g}$ for $15 \mathrm{~min}$ at $4{ }^{\circ} \mathrm{C}$, the plasma was removed and stored at $-20^{\circ} \mathrm{C}$. Meanwhile, livers were quickly sliced and fragments were either used immediately to measure enzyme activities or immediately frozen in liquid $\mathrm{N}_{2}$ for later measurements.

Analytical procedures in serum samples. Plasma alanine aminotransferase (ALT), aspartate aminotranferase (AST), urea and creatinine were measured spectrophotometrically by standard techniques adapted to an Olympus AU-510 analyser (Olympus Diagnostica, Hamburg, Germany). Plasma insulin concentrations were determined by radioimmunoassay (CIS, Biointernational, Gif-Sur-Yvette, France).

Tungsten concentration measurement. To measure tungsten, about $1 \mathrm{~g}$ of serum was weighed and mixed with $3 \mathrm{ml}$ of $65 \%$ nitric acid. The mixture was heated overnight at $60^{\circ} \mathrm{C}$. Afterwards, the temperature was slowly increased to $120^{\circ} \mathrm{C}$ and heated for one hour. Next, the volume was reduced as much as possible by heating at $150{ }^{\circ} \mathrm{C}$. Then, $1 \mathrm{ml}$ of $\mathrm{HClO}_{4}$ was added and the sample was heated at $210^{\circ} \mathrm{C}$ for at least $1 \mathrm{~h}$. After digestion was complete, the sample was totally evaporated by increasing the temperature gradually $\left(10^{\circ} \mathrm{C}\right.$ every $\left.10 \mathrm{~min}\right)$. The sediment was solved with $5 \mathrm{ml}$ of $1 \%$ nitric acid. To measure the concentration of tungsten, an Induced Coupled Plasma- Mass Spectrum (ICP) Perkin-Elmer model Elan-6000 was used.

Assays of enzymes. Glycogen synthase, phosphorylase, glucokinase and pyruvate kinase activities were measured as in our previous work [9], using the methods described in [15, 16, $17,18]$, respectively.
Assay of metabolites. Liver glycogen content, fructose 2,6- $\mathrm{P}_{2}$ and Glc 6-P concentrations were measured as in our previous work [9], using the methods described previously [19, 20, 21].

Histopathological study. Samples of skin, maxillary and mesenteric lymph nodes, salivary glands, thyroid gland, trachea, lungs, heart, sciatic nerve, skeletal muscle, femur, eyes, brain, spinal cord, pituitary gland, oesophagus, stomach, spleen, small and large intestine, pancreas, liver, adrenal glands, kidneys, urinary bladder, testis, seminal glands and aorta were obtained immediately after the rats were killed, fixed for at least $48 \mathrm{~h}$ in $10 \%$ neutral buffered formalin, paraplast-embedded, cut into $5 \mu \mathrm{m}$ sections, and stained with hematoxilin and eosin according to standard procedures [22]. Sections were studied by light microscopy. Additionally, Periodic Acid Shift reaction staining (PAS) was done to detect the presence of glycogen in the epithelial tubular cells of the kidney [23].

Statistical methods. Results are given as means \pm SEM for the indicated number of rats. Comparisons between the different experimental groups were carried out by unpaired Student's $t$ test and ANOVA. Differences were considered statistically significant at a $p$ value of less than 0.05 .

\section{Results}

Effects of tungstate treatment on physical status and blood parameters. Untreated STZ-diabetic rats showed pronounced hyperglycaemia (24.5 \pm $2.3 \mathrm{mmol} / \mathrm{l})$. At the beginning of the experiment, rats were treated with a $0.7 \mathrm{mg} / \mathrm{ml}$ solution of sodium tungstate, which partially reduced glycaemia concentrations, although these did not reach the values of healthy rats. When tungstate concentration was increased to $2 \mathrm{mg} / \mathrm{ml}$, blood glucose concentrations decreased and stabilised around $7.5 \pm 0.3 \mathrm{mmol} / \mathrm{l}$ and were maintained throughout the treatment. Tungstate treatment of healthy rats did not have any significant effect on glycaemia (Fig. 1) (untreated: $4.7 \pm 0.4 \mathrm{mmol} / \mathrm{l}$ vs treated: $4.2 \pm 0.6 \mathrm{mmol} / \mathrm{l})$. Tungstate concentrations in serum were $14.3 \pm 0.9 \mu \mathrm{mol} / \mathrm{l}$ in treated healthy rats and $23.1 \pm 2.7 \mu \mathrm{mol} / \mathrm{l}$ in treated diabetic rats. Untreated rats showed tungstate serum concentrations below the detection limit of the method used $(0.2 \mu \mathrm{mol} / \mathrm{l})$.

Untreated diabetic rats showed a reduced increase in body weight when compared with untreated healthy rats (Fig. 2). When tungstate was given to diabetic rats an initial decrease in growth rate was observed when compared with their untreated counterparts. After two months of treatment, however, the rats recovered their body weight and began to grow at the same rate as the untreated diabetic rats. In healthy rats, the high dose of tungstate slowed the growth rate during the first 2 months, after which the healthy rats grew at a normal rate. At the end of the experiment tungstate-treated healthy rats reached slightly lower body weights than untreated ones (treated: $482 \pm 16$ g vs untreated: $530 \pm 22 \mathrm{~g}$ ).

In untreated diabetic rats, hyperglycaemia was associated with a strong increase in liquid and food con- 


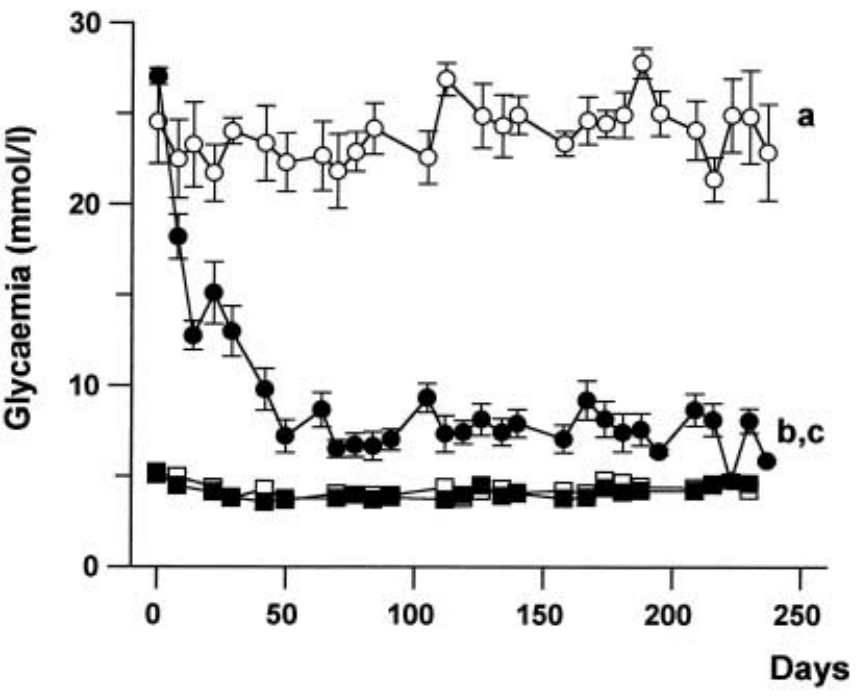

Fig. 1. Effects of tungstate treatment on blood glucose concentrations. During the first 3 weeks rats received a solution of $0.7 \mathrm{mg} / \mathrm{ml}$ and after that, the concentration of tungstate was increased to $2 \mathrm{mg} / \mathrm{ml}$. Glycaemia was measured throughout the treatment. ( $\square$ ) Untreated healthy rats, ( $\square$ ) treated healthy rats, $(\bigcirc)$ untreated diabetic rats and $(O)$ treated diabetic rats. Values are means \pm SEM. ${ }^{a} p<0.0001$ compared with untreated healthy rats ${ }^{b} p<0.0001$ compared with untreated diabetic rats ${ }^{\mathrm{c}} p<0.01$ compared with untreated and treated healthy rats

Table 1. Fluid, food and tungstate intake in treated or untreated diabetic and healthy rats

\begin{tabular}{cccc}
\hline & $\begin{array}{l}\text { Fluid intake } \\
\left(\mathrm{ml} \cdot \mathrm{kg}^{-1} \cdot \mathrm{day}^{-1}\right)\end{array}$ & $\begin{array}{l}\text { Food intake } \\
\left(\mathrm{g} \cdot \mathrm{kg}^{-1} \cdot \mathrm{day}^{-1}\right)\end{array}$ & $\begin{array}{c}\text { Tungstate intake } \\
\left(\mathrm{mg} \cdot \mathrm{kg}^{-1} \cdot \mathrm{day}^{-1}\right)\end{array}$ \\
\hline $\begin{array}{l}\text { Healthy rats } \\
\text { Untreated } \\
(n=12)\end{array}$ & $132 \pm 8$ & $90 \pm 4$ & - \\
$\begin{array}{l}\text { Treated } \\
(n=12)\end{array}$ & $87 \pm 5^{\mathrm{c}}$ & $81 \pm 4$ & $174 \pm 10$ \\
$\begin{array}{c}\text { Diabetic rats } \\
\text { Untreated } \\
(n=6)\end{array}$ & $776 \pm 31^{\mathrm{a}}$ & $166 \pm 8^{\mathrm{a}}$ & - \\
$\begin{array}{l}\text { Treated } \\
(n=12)\end{array}$ & $140 \pm 7^{\mathrm{b}, \mathrm{d}}$ & $95 \pm 3^{\mathrm{b}, \mathrm{d}}$ & $240 \pm 14^{\mathrm{d}}$ \\
\hline
\end{tabular}

Results are expressed as the means \pm SEM for the number of rats indicated in parentheses. These results were calculated when the glycaemia of the rats was stabilised after an increase of tungstate concentration to $2 \mathrm{mg} / \mathrm{ml}$.

${ }^{a} p<0.001$ compared with untreated healthy rats

${ }^{\mathrm{b}} p<0.001$ compared with untreated diabetic rats

${ }^{c} p<0.01$ compared with untreated healthy rats

d $p<0.001$ compared with treated healthy rats

sumption when compared with the untreated healthy rats (Table 1). Tungstate treatment of diabetic rats significantly reduced these parameters to levels similar to those observed in untreated healthy rats. Moreover, in healthy rats, tungstate treatment slightly reduced liquid consumption, whereas it did not significantly alter food intake. Because of the differences in liquid consumption, the amount of tungstate in-

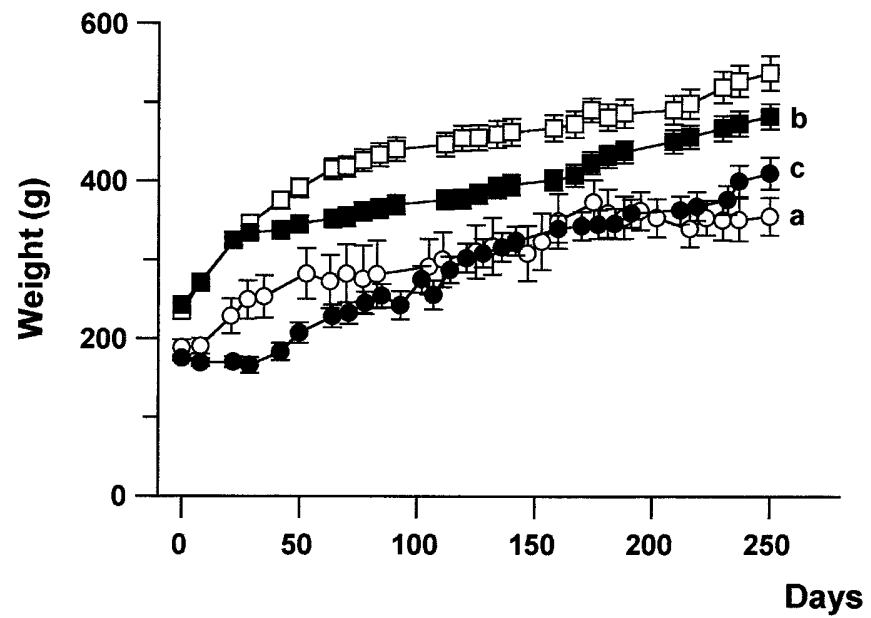

Fig. 2. Effects of tungstate treatment on body weight. The weights of rats were measured throughout the treatment. ( $\square$ ) Untreated healthy rats, $(\boldsymbol{\square})$ treated healthy rats, $(\bigcirc)$ untreated diabetic rats and (O) treated diabetic rats. Values are means \pm SEM. ${ }^{\text {a }} p<0.001$ compared with untreated healthy rats ${ }^{\mathrm{b}} p<0.05$ compared with untreated diabetic rats ${ }^{\mathrm{c}} p<0.001$ compared with treated healthy rats

gested by the treated healthy rats was about $70 \%$ of that ingested by diabetic rats.

Treated diabetic rats had a higher long-term survival rate than their untreated counterparts. At the end of the 8 -months of treatment, $76 \%$ of the treated diabetic rats were still alive while only $50 \%$ of the untreated rats survived. None of the treated healthy rats died during the experiment (Fig. 3).

At the end of the experiment, the rats were killed and several plasmatic parameters were measured. To ascertain whether tungstate induced hepatic or renal damage, the serum activity of ALT and AST and creatinine and urea concentrations were measured (Table 2). In diabetic rats, a more than twofold increase was observed in ALT compared with healthy rats. Tungstate treatment of diabetic rats counteracted this increase. No significant modification in the parameters studied was observed in healthy treated rats, and only a slight increase was detected in the urea concentration of treated diabetic rats. These data indicate that tungstate does not seem to have any appreciable toxic effect on the liver or kidney. Moreover, plasma insulin concentrations were measured. Tungstate treatment did not change the concentration of insulin in either healthy rats or diabetic rats (Table 2).

Effects of tungstate treatment on hepatic metabolism. Diabetes led to the practical abolition of glucokinase activity. Tungstate treatment partially restored this activity to $50 \%$ of that measured in healthy rats (Table $3 \mathrm{~A}$ ). The restoration of this activity in the treated diabetic rats resulted in an increase in Glu 6-P, which reached concentrations similar to those of healthy 


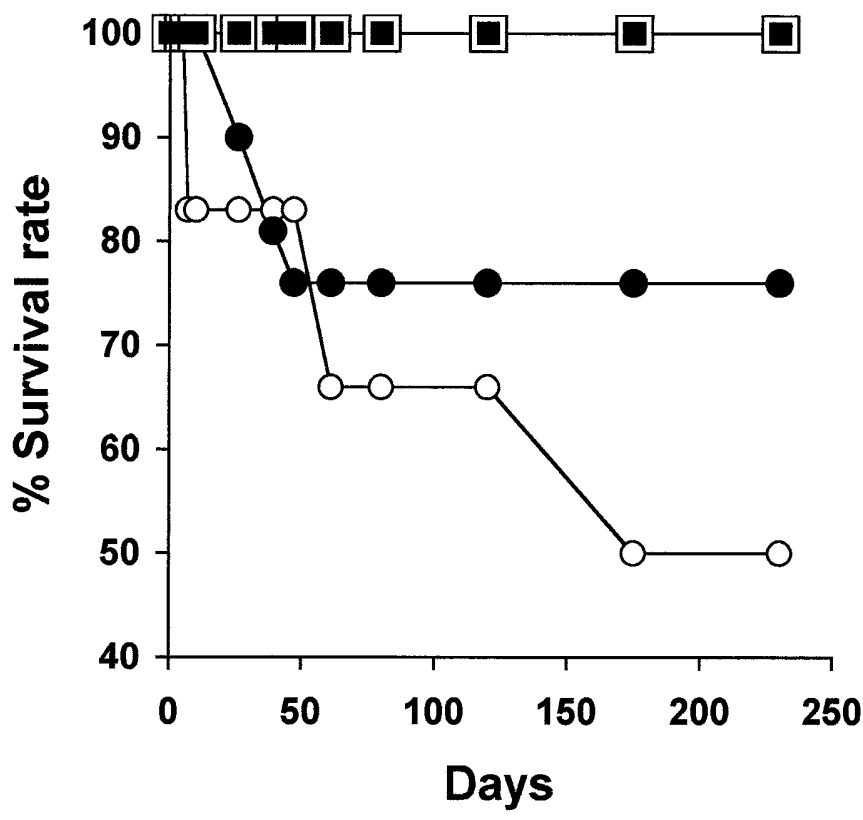

Fig.3. Survival rates. Values expressed as a percentage of rats alive compared with the initial group. ( $\square$ ) Untreated healthy rats, $(\square)$ treated healthy rats, $(\bigcirc)$ untreated diabetic rats and (O) treated diabetic rats

rats. In untreated diabetic rats this metabolite fell to $25 \%$ of healthy rat values (Table 4). Meanwhile, tungstate did not affect glucokinase activity or Glu 6-P concentrations in healthy rats (Tables 3 and 4).

A $65 \%$ reduction in hepatic glycogen content was observed in the untreated diabetic rats when compared with healthy rats. Tungstate treatment completely counteracted this reduction. Treatment did not modify glycogen concentrations in healthy rats (Table 4). The total activity of glycogen synthase, the key enzyme of glycogen synthesis, was much lower $(50 \%)$ in untreated diabetic rats than in healthy rats. Furthermore, the activity ratio (-Glu 6-P/ + Glu 6-P) also decreased in untreated diabetic rats. Tungstate treatment of diabetic rats induced a significant increase in the activity ratio and total activity of glycogen synthase, which reached the levels of healthy rats. In healthy rats, tungstate increased total glyco- gen synthase activity, although the glycogen synthase activity ratio was not modified (Table 3 ). Diabetes induced a $60 \%$ reduction in glycogen phosphorylase $a$ activity when compared with healthy rats. Tungstate treatment of diabetic rats increased this activity to concentrations which were not significantly different from those of healthy rats. Moreover, in healthy rats, tungstate treatment did not significantly modify the activity of glycogen phosphorylase $a$. Moreover, diabetes decreased total pyruvate kinase activity in diabetic rats, but tungstate treatment restored its levels to up to $75 \%$ of those of healthy rat values. Diabetes did not induce any significant change in the pyruvate kinase activity ratio, which was not modified by tungstate treatment (Table 3).

The hepatic concentrations of fructose- $2,6-\mathrm{P}_{2}$ were extremely low in untreated diabetic rats when compared with healthy rats (Table 4). Tungstate treatment did not modify fructose- $2,6-\mathrm{P}_{2}$ content in healthy rats, although it induced a dramatic increase in this parameter in diabetic rats, which reached a similar concentration to those observed in healthy rats.

Histological study. The morphological study of several tissues shows the presence of two types of lesions: those associated with the advanced age of the rats such as chronic progressive nephrosis and focal vacuolar degeneration of hepatic tissue and those specifically associated with diabetes. In the untreated diabetic rats, a bilateral degeneration of the lens, such as hydropic change and fiber necrosis, was observed (Fig. 4A). Moreover, these rats also showed a pronounced vacuolation of the renal tubular epithelium in the innermost cortex (Fig. 4C). These vacuoles were positive with PAS staining, indicating that they were glycogen deposits. These lesions were constant and severe in untreated diabetic rats but were absent in the tungstate-treated diabetic group (Fig. 4B and D). Other tissues were studied and no relevant changes were observed (data not shown). No lesions attributable to tungstate treatment were observed in either treated diabetic or treated healthy rats.

Table 2. Effect of tungstate treatment on various blood parameters

\begin{tabular}{|c|c|c|c|c|c|}
\hline & $\begin{array}{l}\text { ALT } \\
(\mathrm{U} / \mathrm{l})\end{array}$ & $\begin{array}{l}\text { AST } \\
(\mathrm{U} / \mathrm{l})\end{array}$ & $\begin{array}{l}\text { Creatinine } \\
(\mu \mathrm{mol} / \mathrm{l})\end{array}$ & $\begin{array}{l}\text { Urea } \\
(\mathrm{mmol} / \mathrm{l})\end{array}$ & $\begin{array}{l}\text { Insulin } \\
(\mathrm{pmol} / \mathrm{l})\end{array}$ \\
\hline \multicolumn{6}{|l|}{ Healthy rats } \\
\hline Untreated $(n=12)$ & $50 \pm 2$ & $164 \pm 16$ & $73 \pm 2$ & $6.0 \pm 0.3$ & $1100 \pm 150$ \\
\hline \multicolumn{6}{|l|}{ Diabetic rats } \\
\hline Untreated $(n=6)$ & $135 \pm 11^{\mathrm{a}}$ & $178 \pm 11$ & $78 \pm 2$ & $6.1 \pm 0.5$ & $235 \pm 50$ \\
\hline Treated $(n=12)$ & $51 \pm 5^{\mathrm{b}}$ & $151 \pm 10$ & $79 \pm 1$ & $7.4 \pm 0.6^{\mathrm{c}}$ & $300 \pm 60$ \\
\hline
\end{tabular}


Table 3. Effect of tungstate treatment on liver pyruvate kinase, glucokinase activity, liver glycogen synthase and glycogen phosphorylase $a$ activity

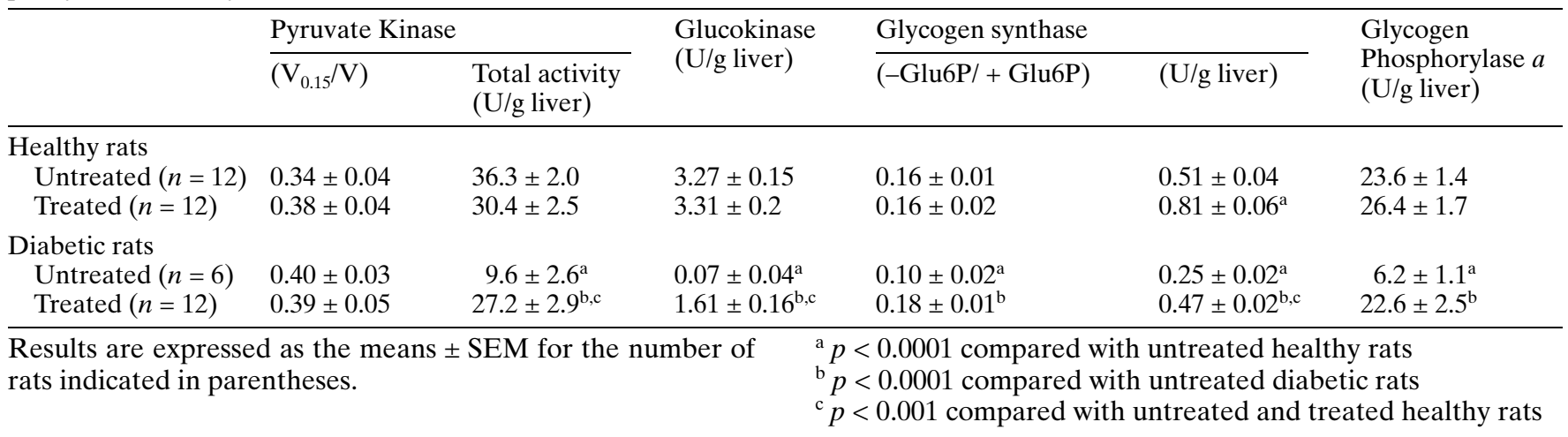

Table 4. Effect of tungstate treatment on liver glycogen, glucose 6-phosphate and fructose 2,6-bisphosphate concentrations

\begin{tabular}{llll}
\hline & $\begin{array}{l}\text { Glycogen } \\
(\mathrm{mg} / \mathrm{g} \text { liver })\end{array}$ & $\begin{array}{l}\text { Glu 6-P } \\
(\mathrm{nmol} / \mathrm{g} \text { liver })\end{array}$ & $\begin{array}{l}\text { Fru-2,6-P } \\
(\mathrm{nmol} / \mathrm{g} \text { liver })\end{array}$ \\
\hline $\begin{array}{l}\text { Healthy rats } \\
\text { Untreated } \\
(n=12)\end{array}$ & $37.5 \pm 2.08$ & $432 \pm 44$ & $6.36 \pm 0.67$ \\
$\begin{array}{l}\text { Treated } \\
(n=12)\end{array}$ & $32.6 \pm 2.39$ & $400 \pm 38$ & $7.0 \pm 0.75$ \\
$\begin{array}{c}\text { Diabetic rats } \\
\text { Untreated } \\
(n=6)\end{array}$ & $14.02 \pm 3.04^{\mathrm{a}}$ & $106 \pm 7^{\mathrm{a}}$ & $0.64 \pm 0.05^{\mathrm{a}}$ \\
$\begin{array}{l}\text { Treated } \\
(n=12)\end{array}$ & $36.14 \pm 3.37^{\mathrm{b}}$ & $365 \pm 39^{\mathrm{b}}$ & $6.55 \pm 0.34^{\mathrm{b}}$ \\
\hline
\end{tabular}

Results are expressed as the means \pm SEM for the number of rats indicated in parentheses.

${ }^{\mathrm{a}} p<0.0001$ compared with untreated healthy rats

${ }^{\mathrm{b}} p<0.0001$ compared with untreated diabetic rats

\section{Discussion}

Our study establishes the efficacy of oral tungstate as a glucose-lowering agent in the long-term treatment of STZ-diabetic rats. This animal model of Type I diabetes is characterised by high hepatic glucose production and low glucose consumption [24]. Tungstate treatment of these rats normalises the glucose hepatic metabolism, which leads to a significant decrease in blood glucose concentrations. These effects were maintained during the whole 8-month treatment, showing that long-term exposure to this compound does not lead to a reduction in its therapeutic action. The treatment also prevents degenerative changes, such as the bilateral degeneration of the lens and a noticeable vacuolation of the renal tubular epithelium in the innermost cortex. These alterations were consistently observed in untreated rats. Furthermore, tungstate clearly increased the survival rate of diabetic rats.

It is worth noting that the normoglycaemic effect of tungstate on this model is not due to an increase in insulin concentrations because no detectable change in immunoreactive basal insulin concentrations was observed after treatment. Moreover, we have not been able to observe an effect of tungstate on insulin secretion in the range of pharmacological concentrations (10-100 $\mu \mathrm{mol} / \mathrm{l})$ (unpublished observations). Because no hyperinsulin-like effects were however, observed in healthy rats, these results support the hypothesis that tungstate action is not mediated through a potentiation of insulin effects.

In a previous report [9] we showed that tungstate was effective in reducing the hyperglycaemia in STZ-diabetic rats after a 2-week course of treatment. In both short-term and long-term experiments, tungstate seems to restore the hepatic glucose metabolism in these rats. Some differences were, however, observed between the two sets of experiments because of the different duration of the treatments. On the one hand, after long-term treatment, diabetic rats showed a higher recovery of glucokinase activity than after short-term treatment (50\% vs $30 \%)$ and a complete restoration of Glu 6-P concentration, thus fuelling sufficient substrate into the glycogen pathway. On the other hand, total glycogen synthase activity decreased in long-term diabetic rats by $50 \%$, a defect not observed in short-term diabetic rats. Nevertheless, tungstate treatment restored not only total glycogen synthase activity and activity ratio but also glycogen phosphorylase $a$ activity. The restoration of these parameters led to the normalisation of glycogen content and metabolism. In healthy rats, tungstate treatment did not have any significant effect on the majority of hepatic glucose metabolism parameters analysed, although an increase in total glycogen synthase activity was observed.

Vanadate, molybdate and selenate are chemically similar to tungstate $[25,26]$ and also have insulinlike effects. Vanadium derivatives are the most widely studied insulinomimetic agents [27-30], although toxic effects, such as dehydration, diarrhea and increases in serum urea and creatinine have been reported in diabetic rats [31-33]. Our results show that long-term tungstate treatment of STZ-diabetic rats 

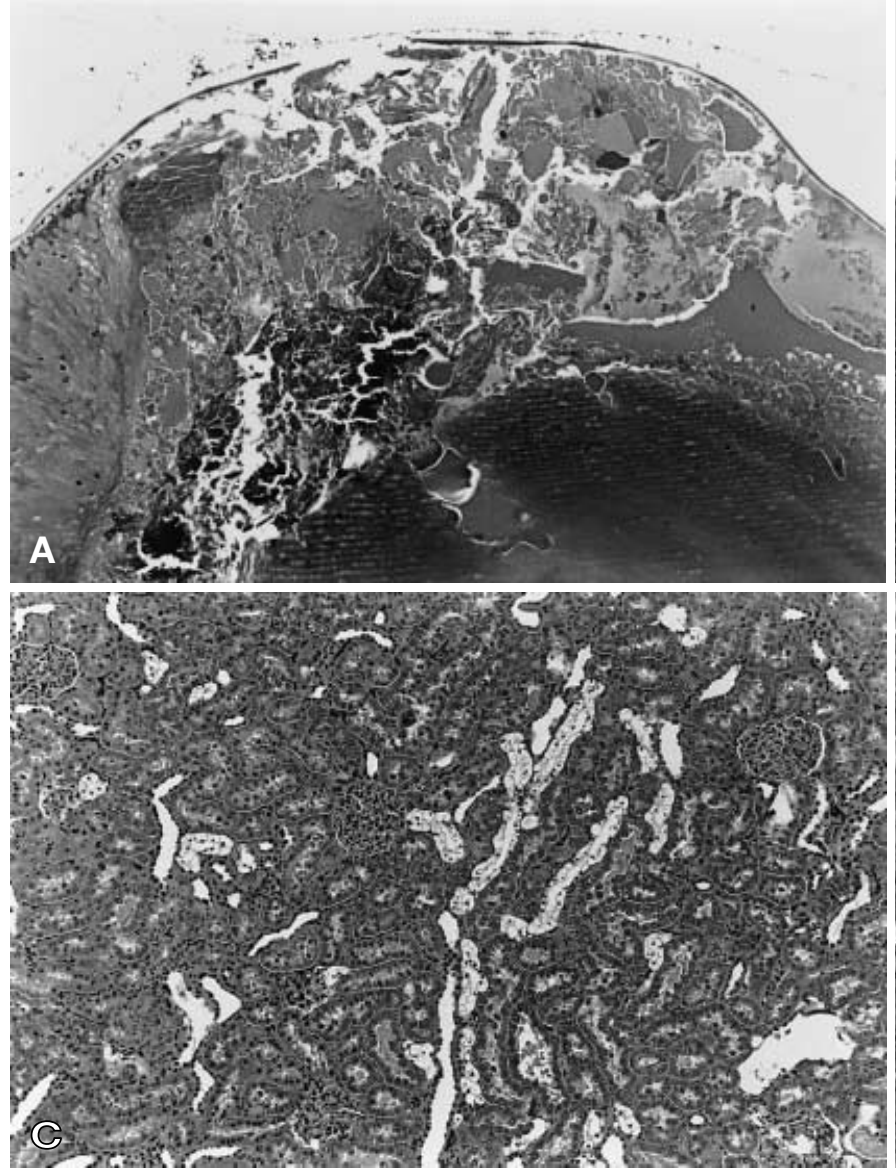

Fig. 4. Morphological study of (A, B) cornea and (C, D) renal tissue in both untreated diabetic rats $(\mathrm{A}, \mathrm{C})$ and treated diabetic $(\mathrm{B}, \mathrm{D})$ rats

did not significantly alter the physical and seric parameters. These results were corroborated by histological studies which did not detect any lesion. Moreover, none of the treated healthy rats died during the 8 -month treatment. Therefore tungstate does not seem to have the negative effects associated with vanadate treatment. This observation has been corroborated by a recently completed toxicological study which shows that tungstate has a low overall toxicity (unpublished data).

In summary, our results support the potential use of sodium tungstate as a new oral treatment for diabetes mellitus, because of its capacity to restore glucose homeostasis and to prevent some diabetes-related complications. Moreover, sodium tungstate shows a significant lack of side effects associated with a long-term application in both treated healthy rats and treated STZ-diabetic rats. It is also worth noting that tungstate does not induce any hypoglycaemic episode in healthy rats, the main drawback of insulin treatment. Some authors have proposed that the short-term goal for diabetes sufferers should be to minimise the risk of hypoglycaemia and thus permit
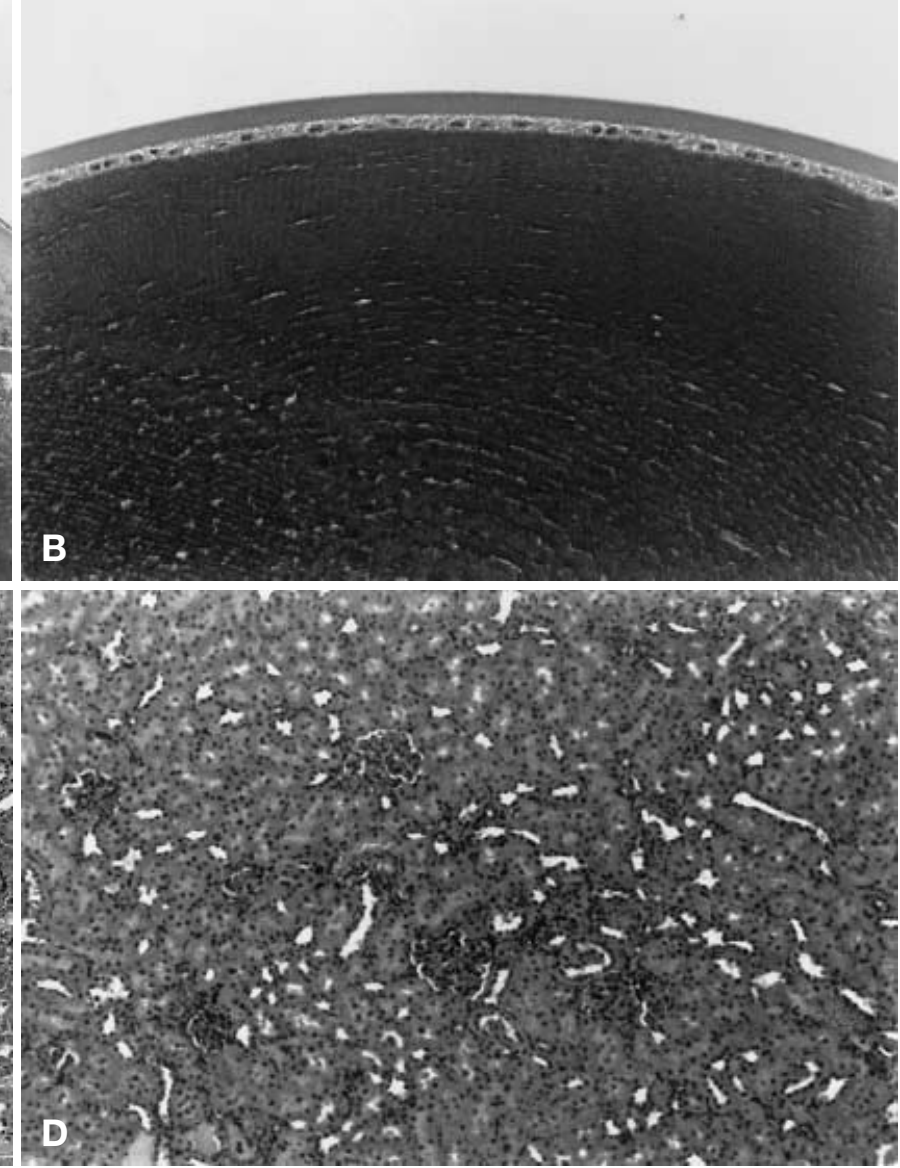

low risk glycaemic control [1]. Because hypoglycaemia is the limiting factor, both conceptually and in practice, tungstate treatment could offer a new approach for the management of diabetes.

Acknowledgements. We thank A. Adrover for her skillful technical assistance and T. Yates for assistance in preparing the English manuscript. This work was supported by Grant P97/2040 from the Health Research Fund (Ministry of Health, Spain). A. Barbera was a recipient of a doctoral fellowship from the Interdepartmental Commission for Research and Technology (Autonomous Government of Catalonia).

\section{References}

1. Cryer PE (1999) Hypoglycaemia is the limiting factor in the management of diabetes. Diabetes Metab Res Rev 15: 42-46

2. Heyliger CE, Tahiliani AG, McNeill TH (1985) Effect of vanadate on elevated blood glucose and depressed cardiac performance of diabetic rats. Science 227: 1474-1476

3. Meyerovitch J, Rothenberg P, Shecter Y, Bonner-Weir S, Kahn CR (1991) Vanadate normalizes hyperglycaemia in two mouse models of non-insulin-dependent Diabetes mellitus. J Clin Invest 87: 1286-1294

4. Miralpeix M, Carballo E, Bartrons R, Crepin K, Hue L, Rousseau GG (1992) Oral administration of vanadate to diabetic rats restores liver 6-phosphofructo-2-kinase content and mRNA. Diabetologia 35: 243-248 
5. Reul BA, Amin SS, Buchet JP, Ongemba LN, Crans DC, Brichard SM (1999) Effects of vanadium complexes with organic ligands on glucose metabolism: a comparison study in diabetic rats. Br J Pharmacol 126: 467-477

6. Cam MC, Rodríguez B, McNeill JH (1999) Distinct glucose lowering and beta cell protective effects of vanadium and food restriction in streptozotocin-diabetes. Eur J Endocrinol 141: 546-554

7. Battell ML, Delgatty HL, McNeill JH (1998) Sodium selenate corrects glucose tolerance and heart function in STZ diabetic rats. Mol Cell Biochem 179: 27-34

8. Becker DJ, Reul B, Ozcelikay AT, Buchet JP, Henquin JC, Brichard SM (1996) Oral selenate improves glucose homeostasis and partly reverses abnormal expression of liver glycolytic and gluconeogenic enzymes in diabetic rats. Diabetologia 39: 3-11

9. Barberà A, Rodríguez-Gil JE, Guinovart JJ (1994) Insulinlike actions of tungstate in diabetic rats. J Biol Chem 269: 20047-20053

10. Barberà A, Fernández-Alvarez J, Truc A, Gomis R, Guinovart JJ (1997) Effects of tungstate in neonatally-streptozotocin-induced diabetic rats: mechanism leading to normalization of glycaemia. Diabetologia 40: 143-149

11. Reul BA, Becker DJ, Ongemba LN, Bailey CJ, Henquin JC, Brichard SM (1997) Improvement of glucose homeostasis and hepatic insulin resistance in ob/ob mice given oral molybdate. J Endocrinol 155: 55-64

12. Ozcelikay AT, Becker DJ, Ongemba LN, Pottier AM, Henquin JC, Brichard SM (1996) Improvement of glucose and lipid metabolism in diabetic rats treated with molybdate. Am J Physiol 270: E344-E352

13. Halberstam M, Cohen N, Shlimovich P, Rossetti L, Shamonn H (1996) Oral vanadyl sulphate improves insulin sensitivity in NIDDM but not in obese nondiabetic subjects. Diabetes 45: 659-666

14. Goldfine AB, Patti ME, Zuberi L et al. (2000) Metabolic effects of vanadyl sulfate in humans with non-insulin-dependent Diabetes Mellitus: in vivo and in vitro studies. Metabolism 49: 400-410

15. Thomas JA, Schlender KK, Larner J (1968) A rapid filter paper assay for UDP-glucose-glycogen glucosyltransferase, including an improved biosynthesis of UDP $\left\{{ }^{14} \mathrm{C}\right\}$ glucose. Anal Biochem 25: 486-499

16. Gilboe DP, Larson KL, Nuttall FQ (1972) Radioactive method of the assay of glycogen phosphorylase. Anal Biochem 47: 20-27

17. Newgard CB, Hirsch LJ, Foster DW, McGarry, JD (1983) Studies on the mechanism by which exogenous glucose is converted into liver glycogen in the rat. J Biol Chem 258: $8046-8052$

18. Feliu JE, Hue L, Hers HG (1977) Regulation in vitro and in vivo of adenosine 3'-5'-monophosphate-dependent inacti- vation of rat liver pyruvate kinase type L. Eur J Biochem 81: 609-617

19. Chan TM, Exton JH (1976) A rapid method for the determination of glycogen content and radioactivity in small quantities of tissue or isolated hepatocytes. Anal Biochem 71: $96-105$

20. Van Shaftingen E, Lederer B, Bartrons R, Hers HG (1982) A kinetic study of pyrophosphate: fructose-6-phosphate phosphotransferase from potato tubers. Applications to a microassay of fructose 2,6-bisphosphate. Eur J Biochem 129: 191-195

21. Lang G, Michal G (1974) D-Glucose-6-phosphate and DFructose-6-phosphate. In: Bergmeyer HU (ed) Methods of Enzymatic Analysis vol 3. Academic Press, New York, pp 1238-1242

22. Ross MH, Reith EJ, Romrell LJ (1989) In: Histology. A Text an Atlas (ki sp k) Williams \& Wilkins, Baltimore, Maryland, USA, chapter 1, pp 1-2

23. Pearse AGE (1985) In: Histochemistry Theoretical and Applied, vol 2 (Pearse, AGE) Churchill Livingstone. Edinburgh, pp 675-785

24. Burceline R, Eddouks M, Maury J, Kande J, Assan R, Girard J (1995) Excessive glucose production, rather than insulin resistance, accounts for hyperglycaemia in recent-onset streptozotocin-diabetic rats. Diabetologia 38: 283-290

25. Cotton FA, Wilkinson G (1988) In: Advanced Inorganic Chemistry. Wiley-Interscience, New York, pp 665-679 and pp 804-847

26. Kendercik MJ, May MT, Plishka MJ, Robinson KD (1992) In: Metals in Biological Sciences. Ellis Horwood Ltd. Chirchester, pp 121-128

27. Thompson KH (1999) Vanadium and diabetes. Biofactors 10: 43-51

28. Poucheret P, Verma S, Grynpas MD, McNeill JH (1998) Vanadium and diabetes. Mol Cell Biochem 188: 73-80

29. Brichard SM, Henquin JC (1995) The role of vanadium in the management of diabetes. Trends Pharmacol Sci 16 : 265-270

30. Shechter Y, Shisheva A (1993) Vanadium salts and the future treatment of diabetes. Endeavour 17: 27-31

31. Domingo JL (2000) Vanadium and diabetes What about vanadium toxicity? Mol Cell Biochem 203: 185-187

32. Domingo JL, Gomez M, Sanchez DJ, Llobet JM, Keen Cl (1995) Toxicology of vanadium compounds in diabetic rats: the action of chelating agents on vanadium accumulation. Mol Cell Biochem 153: 233-240

33. Domingo JL, Gomez M, Llobet JM, Corbella J, Keen Cl (1991) Oral vanadium administration to streptozotocin-diabetic rats has marked negative side effects, which are independent of the form of vanadium used. Toxicology 66: 279-287 